\title{
Multiculturalismo e educação intercultural: narrativas de professores sobre preconceito e abordagens culturais na escola
}

\author{
Multiculturalism and intercultural education: teachers' \\ narratives about prejudice and cultural approaches in school
}

\begin{abstract}
Caio Roberto Siqueira Lamego
Mestre em Ensino de Ciências, Ambiente e Sociedade pela Universidade do Estado do Rio de Janeiro (UERJ). Docente da Secretaria de Estado de Educação e da Secretaria Municipal de Educação e Cultura de Itaboraí, RJ - Brasil caiolamego@gmail.com
\end{abstract}

Maria Cristina Ferreira dos Santos Doutora em Educação. Professora Adjunta da Universidade do Estado do Rio de Janeiro. Docente dos Programas de Pós-Graduação em Ensino de Ciências, Ambiente e Sociedade e de Ensino em Educação Básica na UERJ, RJ - Brasil mariacristinaf@gmail.com

Resumo: Considerando a importância da compreensão de dinâmicas de sujeitos socioculturais na escola, o objetivo desse estudo foi compreender como professores abordam questões culturais e situações de preconceito e discriminação na escola. A pesquisa teve abordagem qualitativa e foram realizadas entrevistas com cinco docentes que atuavam na educação básica desenvolvendo projetos relacionados à diversidade cultural. A análise das narrativas apontou experiências de preconceito e discriminação racial, religiosa, de gênero e sexualidade e a utilização de práticas dialógicas pelos professores ao abordar questões culturais no cotidiano escolar. Destaca-se a importância do diálogo crítico-reflexivo na formação emancipatória de professores, contribuindo para a problematização da lógica monocultural estabelecida. Esse estudo contribui com reflexões sobre questões culturais que permeiam a escola e destaca práticas dialógicas como estratégia para uma escola menos excludente.

Palavras-chave: Diversidade cultural. Interculturalidade. Educação básica.

\begin{abstract}
Considering the importance of understanding the dynamics of sociocultural subjects in school, the purpose of this study was to understand how teachers approach cultural issues and situations of prejudice and discrimination in school. The research had a qualitative approach and interviews were conducted with five teachers who worked in elementary education developing projects related to cultural diversity. The narratives' analysis point to experiences of racial, religious, gender and sexuality prejudice and discrimination. Teachers reported adopting dialogic practices in addressing cultural issues in school. The analysis highlights the importance of critical-reflexive dialogue in the emancipatory formation of teachers, contributing to the problematization of established monocultural logic. This study contributes with reflections on cultural issues that permeate the school and highlights dialogic practices as strategy for a less excluding school.
\end{abstract}

Keywords: Cultural diversity. Interculturality. Elementary education. 


\section{Introdução}

Estudos que contribuem para a compreensão das dinâmicas de sujeitos socioculturais em espaços educativos tornam-se importantes, uma vez que nesse campo há "[...] a possibilidade de se abordar de forma mais ampla, complexa e plurifacetada a educação, os processos pedagógicos, os sujeitos implicados, as fronteiras construídas pelas ordens discursivas dominantes" (COSTA, 2010, p. 135). O diálogo entre culturas no ambiente escolar tem possibilitado mapear aspectos da identidade das minorias, a diferença e a tolerância que formam pilares da educação intercultural. Moreira e Candau (2003) afirmam que a relação existente entre escola e cultura está presente em todo processo educativo. Esses autores ressaltam a importância da construção de um currículo com novas posturas, saberes, objetivos, conteúdos, estratégias e formas de avaliação, entendendo a cultura como centro do processo de ensino e aprendizagem.

Nos últimos anos as produções acadêmicas têm se debruçado sobre questões culturais em diferentes espaços educativos. É preciso atentar para tensões entre os diferentes sujeitos socioculturais que compõem a escola e questionar desigualdades, preconceitos, discriminações e exclusões, ensejando a busca de diálogo e valorização das características que diferenciam grupos sociais.

Ao colocar a cultura como o centro de debates sobre diferenças, buscam-se reflexões sobre sociedade e educação, representando desafios e conquistas no atual cenário educacional. Para Moreira e Candau (2003), a escola é um ambiente caracterizado pela pluralidade cultural em que relações entre diferentes culturas geram tensões e conflitos, e que muitas vezes tende a silenciar ou neutralizar as diferenças pela dificuldade de lidar com a diversidade cultural existente. Segundo Queiroz e Neves (2017, p. 80), a postura homogeneizadora favorece a multiplicação de "[...] preconceitos, discriminações e episódios de violência física, provocados por confrontos entre identidades culturais relativas à raça, etnia, gênero, confissão religiosa, orientação sexual, geração, deficiência física e comunidades de referência".

A partir do reconhecimento das diferenças emergem debates e reflexões sobre a "igualdade na diferença", pois, como afirma Candau (2008, p. 49), “[ . . ] não se trata de, para afirmar a igualdade, negar a diferença, nem de uma visão diferencialista absoluta, que relativize a igualdade”. A partir de uma visão dialética 
e reflexiva sobre igualdade e diferença, fomentam-se debates sobre a diversidade cultural na sociedade contemporânea (MOREIRA; CANDAU, 2003).

O debate multicultural surgiu no âmbito das lutas dos grupos sociais discriminados e marginalizados e em movimentos sociais que buscavam dar voz às minorias. Candau (2014) reconhece três perspectivas de multiculturalismo: multiculturalismo assimilacionista, que busca integrar os sujeitos socioculturais à cultura hegemônica, sem problematizar a ação homogeneizadora; multiculturalismo diferencialista ou monoculturalismo plural, que favorece a ênfase na diferença, mas resguardando contextos e espaços próprios daquela identidade cultural e favorecendo o isolamento de culturas "homogeneizadas"; e o multiculturalismo interativo, também denominado de interculturalidade, cujo objetivo é promover interação sociocultural entre diferentes grupos de uma sociedade, com debate sobre diferenças e desigualdades. Na perspectiva da educação intercultural, Walsh (2009) propõe três diferentes concepções: a) relacional, que apresenta um contato básico e geral no intercâmbio entre as distintas formas de culturas; b) funcional, que reconhece a diversidade cultural e as diferenças, com o intuito de inclusão em uma estrutura social estabelecida; c) crítica, que prevê a necessidade de mudança não só entre as relações sociais, mas também na construção histórica de preconceitos e discriminações que se apoiam na tríade estruturalcolonial-racial. Para Candau (2014, p. 38), a interculturalidade crítica questiona a visão essencialista das diferentes culturas e identidades, concebendo-as "[. . . em contínuo processo de elaboração, construção e reconstrução".

O termo pluralidade cultural está relacionado ao reconhecimento de características étnicas e culturais de um grupo social, podendo ser utilizado como sinônimo de diversidade cultural (CANDAU, 2011; MOREIRA; CARVALHO, 2014). Alguns autores fazem distinção entre os dois termos, relacionando a pluralidade cultural à proposta curricular e a diversidade cultural às diferenças dos sujeitos na escola (MOREIRA; CANDAU, 2003). Saberes, práticas e metodologias utilizados para trabalhar questões referentes à diversidade cultural são denominados abordagens culturais por esses autores. Neste estudo, optou-se por utilizar esses sentidos aos termos explicitados.

Com apoio em Candau (2014), esse estudo inclina-se na perspectiva intercultural para compreender a inter-relação de sujeitos socioculturais no ambiente escolar, na valorização e reconhecimento de diferenças dos sujeitos socioculturais, na interação do que o "eu" chama de "outro", a fim de minimizar a discriminação 
e os preconceitos. Busca-se entender, por meio da análise de narrativas, como os professores abordam questões culturais e situações de preconceito e discriminação vivenciadas na escola.

\section{Metodologia}

A pesquisa teve abordagem qualitativa, buscando-se compreender " [... $]$ o universo dos significados, dos motivos, das aspirações, das crenças, dos valores e atitudes" (MINAYO, 2013, p. 21) de um determinado grupo social e apresenta caráter exploratório, proporcionando uma " [. . . ] visão geral, de tipo aproximativo, acerca de determinado fato" (GIL, 2012, p. 27).

Esse estudo foi desenvolvido com professores que atuavam em uma escola pública que oferece as modalidades de ensino normal e regular, com os níveis de ensino fundamental e médio, no estado do Rio de Janeiro. Nos anos de 2016 e 2017, cerca de 110 professores regentes lecionavam nessa escola e inicialmente foram convidados para participar da pesquisa alguns professores/as que realizavam atividades ligadas a questões culturais. Para a indicação de outros participantes, foi utilizada a metodologia "bola de neve" (snowball), que possibilita a listagem de possíveis sujeitos que farão parte do universo da amostra a partir de outros sujeitos pesquisados (BERNARD, 2006). Dentro deste universo amostral, foram selecionados, para a realização de entrevistas, docentes que indicaram abordar questões culturais. As entrevistas têm por finalidade aprofundar as questões e contribuem para compreender a lógica da informação disponibilizada pelo entrevistado por meio da captação imediata dos dados (MINAYO, 2013; GIL, 2012). Por meio da realização de entrevistas individuais, buscou-se compreender as abordagens culturais mobilizadas pelos professores na educação básica. Para o registro desses dados, as entrevistas foram gravadas e, posteriormente, transcritas.

O projeto de pesquisa foi apresentado à direção da escola, que concordou com sua realização segundo o Termo de Anuência, e também para os professores selecionados. Aqueles que concordaram em participar da pesquisa foram convidados a assinar o Termo de Consentimento Livre e Esclarecido (TCLE), sendo garantido o sigilo da identidade dos participantes, de acordo com as normas éticas de pesquisa. 
Foram entrevistados cinco professores/as: dois professores de Ciências/ Biologia (PCB1 e PCB2), uma professora de Geografia (PG), uma professora de Disciplinas Pedagógicas (PP) e uma professora de História (PH). A escolha desses professores/as se justifica por eles/as desenvolverem projetos que discutiam questões culturais, preconceito e discriminação na escola. Nas entrevistas eles/ as foram questionados/as sobre atividades que desenvolviam na escola relacionadas a abordagens culturais; se haviam presenciado situações de preconceito ou discriminação nesse ambiente e como se posicionaram; e quais obstáculos e desafios vivenciaram na promoção de abordagens culturais em suas práticas didático-pedagógicas. As narrativas foram analisadas no sentido de compreender as percepções dos/as professores/as sobre situações de preconceito e/ou discriminação experienciadas e abordagens utilizadas.

\section{Narrativas docentes sobre preconceito e abordagens culturais}

Os depoimentos dos/as professores/as foram transcritos e analisados em relação a abordagens culturais, preconceito e discriminação na escola. Os/As professores/as identificaram a necessidade de debater questões que dialogavam com relações étnico-raciais, diversidade religiosa, gênero, sexualidade e preconceito social vinculado ao local de moradia de alguns sujeitos da escola:

[...] Em relação à cultura, o (...) exemplo que eu poderia citar aqui é a religião (PCB1).

[...] Eu tento trabalhar com eles não só o diferente, mas o reconhecimento dos seus iguais, porque às vezes eles acham que 0 "cara" é muito diferente deles e não é, e isso é legal (PG).

[...] Eu posso dizer que o meu trabalho aqui nesta instituição está impregnado com essa pluralidade cultural (...). É esse eixo que me dá uma identificação dentro desta instituição (PP).

[...] temos visto um retrocesso muito grande, uma intolerância no mundo em relação à religião, a gênero, a cor; então, o tempo 
inteiro esse é um assunto que temos que continuar debatendo, não acaba nunca [...] (PH).

Nas narrativas, os professores destacaram questões que envolviam relações étnico-raciais, religiosas, de gênero e sexualidade e apontaram o aumento da intolerância no ambiente escolar. A sensibilidade dos entrevistados para essas questões e o reconhecimento do outro como "igual" favoreceram a discussão sobre preconceito e discriminação na escola. Para que a tolerância seja um processo construído por meio do diálogo, Candau (2014, p. 40) propõe uma mediação pedagógica capaz de "[...] promover processos sistemáticos de interação com os 'outros', sem caricaturas nem folclorização" das diferentes identidades étnicas, de pertencimento social, de gênero, entre outros, valorizando um debate engajado na luta ao direito à diferença.

Os cinco entrevistados relataram haver presenciado preconceito e discriminação na escola. Em suas narrativas, eles indicaram preconceito racial, religioso, homofobia e machismo, e quatro afirmaram notar predominância de preconceito racial entre os alunos.

Já vi preconceito religioso e racial. Por exemplo, uma menina do candomblé precisou vir de branco, seguindo os rituais dela, e sofreu muito preconceito (PCB2).

\section{[...] O que mais aparece é o preconceito racial (PCB1).}

Hoje os próprios alunos têm preconceito com o outro, chamando de pretinha, de cabelo ruim, disso e daquilo (PH).

As políticas assimétricas que permeiam os diferentes sujeitos socioculturais legitimam a supremacia dos grupos sociais hegemônicos. Segundo Gomes (2013, p. 73), a elite, ao se destacar na sociedade e promover o movimento de "branquitude", constrói "[...] um imaginário extremamente negativo sobre o negro, que solapa a identidade racial, danifica sua autoestima, culpa-o pela discriminação que sofre e ainda justifica as desigualdades raciais". Nesse sentido, torna-se importante que a escola proponha estratégias para favorecer diálogos e reflexões sobre as questões étnico-raciais. 
Um professor apontou a escola como espaço de desconstrução do preconceito racial: "[. . . A A escola pode servir como local para desconstruir essa mentalidade, essa cultura distorcida e associar a questão racial como caráter" (PCB1). O posicionamento desse docente em relação ao preconceito e discriminação se aproxima de Gomes (2013, p. 69), entendendo que a escola exerce papel fundamental para a "[...] construção de representações positivas dos afro-brasileiros e por uma educação que tenha o respeito à diversidade como parte de uma formação cidadã e anti-racista".

Uma entrevistada afirmou que o machismo era o preconceito que se destacava na escola: "Já presenciei racismo, homofobia, mas destaco o machismo [. . .]" (PG, 2017). Segundo Saavedra et al. (2003, p. 23), "[. . .] as relações de gênero [grifo dos autores] ainda estão marcadas pela desigualdade e pela hierarquização baseada na diferença entre os sexos e legitimada pela superioridade do masculino sobre o feminino e do heterossexual como forma de viver a sexualidade". Dessa forma, é importante a reflexão sobre as questões de gênero e sexualidade no campo do currículo, de forma a possibilitar a diminuição do estigma e de estereótipos simbólicos. Mesmo com a crescente abordagem de questões relativas a gênero e sexualidade no ambiente escolar, com a militância de grupos discriminados e excluídos pela sociedade (CANDAU, 2008), ainda será necessário avançar para que essas temáticas se consolidem na pesquisa e práticas educacionais no espaço escolar.

Os/As entrevistados/as explicaram como reagiram quando vivenciaram situações de preconceito na escola:

O que eu pude fazer foi estudar um pouco mais até mesmo para eu me posicionar em sala [. . . Temos que achar um ponto de diálogo para que não fiquemos iguais a "porco espinho" (PCB2).

[...] Não vou sair por aí discutindo com as pessoas, dizendo que elas estão erradas da forma que pensam e o que eu tento fazer é trabalhar com os meus alunos em sala de aula [...] (PH).

Aponta-se que esses professores desenvolveram práticas educativas para trabalhar as relações interpessoais a partir dos conflitos e da valorização do diálogo, centrando na visibilidade no aluno e respeitando as diferenças no grupo. Compreendendo que construir um espaço que busca discutir o preconceito 
e discriminação é "[...] uma tarefa difícil, mas indispensável a todos aqueles que querem construir um mundo de maior respeito à dignidade humana" (SAAVEDRA et al., 2003, p. 17), práticas educativas dialógicas são estratégias que se aproximam da educação intercultural e podem ser concebidas como "[...] alternativas democráticas a se adotar perante as visões etnocêntricas e excludentes que pautam a gestão social na atualidade" (QUEIROZ; NEVES, 2017, p. 82).

Os obstáculos para a abordagem de questões relativas à diversidade cultural na escola foram indicados pelos cinco professores entrevistados. Para os professores PP e PH, o maior obstáculo consistia na falta de infraestrutura e de material para o desenvolvimento das atividades pedagógicas. Para os demais professores, o principal obstáculo eram as crenças religiosas, no sentido de limitar o diálogo nos espaços escolares.

[...] Eu procuro fazer um trabalho envolvendo o diálogo e sem impor nada [...] e sem querer atacar a religião ou concepção de ninguém, esclarecer alguns conceitos para os alunos (PCB1).

[...] Acho que as questões religiosas são as piores porque quanto mais o indivíduo cria uma doutrina menos aceita o outro (PCB2).

[...] Conseguir discernir entre seguir uma ideologia, uma proposta ou um dogma e isso não sair do diálogo do preconceito é um problema. Muitos religiosos trazem essa proposta, e em qualquer segmento, e reafirmam o preconceito a partir do momento que essas pessoas são fundamentalistas (PG).

Os professores ressaltaram que o fundamentalismo religioso, por vezes, corrobora para o conflito entre a visão científica e religiosa, influenciando na aprendizagem dos alunos. Concordando com Barcellos e Andrade (2014, p. 6), o confronto entre religiões se dá pela "[ . . . resistência às expressões religiosas hegemônicas na escola", que, em última análise, demonstra que "[...] as religiões cristãs são concorrenciais, expansionistas e proselitistas".

Os professores apontaram que uma metodologia dialógica auxiliava no desenvolvimento de atividades que abordavam diferentes questões culturais no cotidiano dessa escola, aproximando-se de ações multiculturais que têm por 
objetivo promover uma educação escolar que "[. . . ] supõe repensar seus diferentes componentes e romper com a tendência homogeneizadora e padronizada" (CANDAU, 2014, p. 37) no contexto do cotidiano escolar. Considerando as diferentes concepções de multiculturalismo, as práticas dialógicas dos professores se inserem em uma perspectiva intercultural (CANDAU, 2014), visando minimizar o preconceito e discriminação na escola, a partir de um debate sobre igualdade e diferença, sem reduzi-las a polos distintos.

A escola é marcada pela diversidade cultural, onde diferentes sujeitos expressam suas culturas e identidades, sendo fundamental pensá-la como local que promova uma "[...] educação que favoreça a inter-relação dos diferentes grupos sociais e culturais, na perspectiva da igualdade, e que a promova positivamente, através de práticas pedagógicas democráticas" (SAAVEDRA et al., 2003, p. 29). É importante pensar uma formação pedagógica que se preocupe em formar sujeitos críticos capazes de promover diálogos que incluam a diversidade como tema central para as reflexões e ressignificações das práticas pedagógicas, contribuindo para uma escola menos excludente e aberta ao diálogo entre diferentes culturas e identidades.

\section{Considerações finais}

Nesse estudo, buscou-se compreender relações estabelecidas por professores envolvendo questões referentes à diversidade cultural em uma escola no estado do Rio de Janeiro. A análise dos depoimentos de cinco professores/as indicou que a perspectiva intercultural estava presente no desenvolvimento de projetos visando diminuir o preconceito e a discriminação na escola, a fim de valorizar e dar voz a grupos subalternizados e inferiorizados historicamente. Mesmo com a realização de projetos e de debates sobre questões étnico-raciais, foram relatadas atitudes preconceituosas em relação às questões raciais entre os alunos. Nas narrativas docentes foram indicados obstáculos para lidar com questões relativas à diversidade cultural na escola, como a dificuldade em abordar os avanços no conhecimento científico de diferentes disciplinas em função das crenças religiosas dos alunos.

Nas narrativas de professores foi identificada a busca por estratégias didático-pedagógicas que visavam ao diálogo e reflexões sobre questões culturais 
no ambiente escolar. Algumas questões apontadas pelos professores entrevistados necessitam de aprofundamento na investigação para a compreensão das diferentes realidades vivenciadas pelos sujeitos. Aponta-se que o diálogo crítico-reflexivo em uma formação emancipatória de professores pode contribuir para a problematização da lógica monocultural estabelecida, potencializando a percepção para demandas que emergem da escola. Outras epistemologias podem aproximar perspectivas disciplinares e pedagógicas de questionamentos sobre abordagens culturais na educação básica. Finalizando, este estudo contribui com reflexões sobre questões culturais que permeiam a escola e aponta a utilização de práticas dialógicas como estratégia para uma escola menos excludente.

\section{Agradecimentos}

Os pesquisadores agradecem aos professores que concordaram em participar deste estudo.

\section{Referências}

BARCELLOS, J.; ANDRADE, M. A religião entra na escola pública: uma análise da intolerância religiosa na escola. In: XVI Encontro Nacional de Didática e Práticas de Ensino. Anais. . 2014, p. 1-13.

BERNARD, H. R. Research methods in anthropology: qualitative and quantitative approaches. 4th ed. New York: Altamira Press, 2006. 803 p.

CANDAU, V. M. F. Ser professor/a hoje: novos confrontos entre saberes, culturas e práticas. Revista Educação, v. 37, n. 1, p. 33-41, 2014.

CANDAU, V. M. F. Diferenças culturais, cotidiano escolar e práticas pedagógicas. Revista Currículo sem Fronteiras, v. 11, n. 2, p. 240-255, 2011.

CANDAU, V. M. F. Multiculturalismo e educação: desafios para a prática pedagógica. In: MOREIRA, A.F.B.; CANDAU, V.M.F. (Org.). Multiculturalismo: diferenças culturais e práticas pedagógicas. 2. ed. Petrópolis, RJ: Vozes, 2008. p. 13-37.

COSTA, M. V. Sobre as contribuições das análises culturais para a formação dos professores do início do século XXI. Revista Educar, 37, p. 129-152, 2010.

GIL, A. C. Como elaborar projetos de pesquisa. 6. ed. São Paulo: Atlas, 2012. 200 p. 
GOMES, N. L. A questão racial na escola: desafios colocados pela implementação da Lei 10.639/03. In: MOREIRA, A. F. B.; CANDAU, V. M. F. (Org.). Multiculturalismo: diferenças culturais e práticas pedagógicas. 10. ed. Petrópolis, RJ: Vozes, 2013. p. 67-89.

MINAYO, M. C. S. Pesquisa social: teoria, método e criatividade. 33. ed. Petrópolis, RJ. Vozes, 2013 .

MOREIRA, A. F.; CARVALHO, M. Construção de identidades no currículo de uma escola de Ensino Fundamental. In: MOREIRA, A. F.; CANDAU, V. M. (Org.). Currículos, disciplinas escolares e culturas. Petrópolis, RJ: Vozes, 2014. p. 42-76.

MOREIRA, A. F. B.; CANDAU, V. M. Educação escolar e cultura(s): construindo caminhos. Revista Brasileira de Educação, 23, p. 156-168, 2003.

QUEIROZ, P. P.; NEVES, F. H. G. Sociologia escolar e culturas: reflexividade crítica e educação intercultural. Revista Interdisciplinar em Cultura e Sociedade, São Luís, 3, Número especial, p. 79-98, 2017.

SAAVEDRA, A. et al. In: CANDAU, V. M. F. (Org.). Somos tod@s iguais? Escola, discriminação e educação em direitos humanos. Rio de Janeiro: DP\&A, 2003. p. 15-31.

WALSH, C. Interculturalidad crítica y educación intercultural. In: VIAÑA, J.; TAPIA, L.; WALSH, C. (Org.) Construyendo interculturalidad crítica, La Paz: Instituto Internacional de Integración, 2009. p. 75-96. Disponível em: <http://www.uchile.cl/documentos/ interculturalidad-critica-y-educacion- intercultural_110597_0_2405.pdf > . Acesso em: 10 fev. 2018.

recebido em 17 jun. 2018 / aprovado em 18 jul. 2018

Para referenciar este texto:

LAMEGO, C. R. S.; SANTOS, M. C. F. Multiculturalismo e educação intercultural: narrativas de professores sobre preconceito e abordagens culturais na escola. Dialogia, São Paulo, n. 29, p. 111-121, mai./ago. 2018. Disponível em: <https://doi.org/10.5585/Dialogia.n29.8810>. 
